\title{
DIARRHOEA AS A MEDICAL EMERGENCY IN THE FIELD
}

\author{
Captain B. D. BONAR, M.B., B.Ch., B.A.O., R.A.M.C. \\ Medical Reception Station, Osnabruck
}

SUMMARY: In a Battle Group exercise in North Africa involving approximately 850 men there were 543 cases of diarrhoea, over a four-week period. Two patients developed catastrophic diarrhoea, one of whom almost expired from hypovolaemic shock. The case history of the latter is described. The importance of adequate preparation for such an emergency is stressed.

\section{Introduction}

In July 1969 I went to North Africa with a Battle Group on an exercise lasting four weeks. The total strength of the Group was about eight hundred and fifty men. It was realised that hazards to health in moving from a temperate to a hot desert climate would include the effects of heat and diarrhoea. Due to continuous propaganda and good unit discipline morbidity was low from heat-induced illness. Diarrhoea proved to be a serious problem, the greatest incidence being in the first week of the exercise (Fig. 1).

In most cases the only presenting symptom was diarrhoea. Recovery within twentyfour hours on chalk and opium, tabs two, four times daily, was usual. There was no loss of efficiency in the Battle Group due to these patients. Eighteen patients presented with diarrhoea, vomiting, crampy abdominal pain and a moderate fever. These were treated with phthalysulphathiazole eight grammes daily. They recovered in forty-eight to seventy-two hours and were a drain on Battle Group strength. There were two cases of catastrophic diarrhoea, one of whom almost expired from hypovolaemic shock.

\section{Case Report}

Gunner T., aged 18 years, presented at the Regimental Aid Post deep in the desert, complaining of nausea, vomiting, abdominal pain and diarrhoea. He felt weak and was thirsty. His symptoms had been present for about two hours. Physical examination revealed an anxious, lightly-built soldier who was alert and co-operative. His temperature was $97^{\circ} \mathrm{F}$, pulse rate 90 per minute, of good volume and regular. His tongue was dry and furred. No abnormality was noted on cardiac or pulmonary auscultation. General abdominal guarding and tenderness were present; there was no rebound tenderness in the right iliac fossa and no masses were palpable. Liver, spleen and kidneys were not enlarged. Bowel sounds were present. On digital rectal examination no abnormalities were noted. His blood pressure could not be established as the mercury sphygmomanometer had been damaged in transit through the desert.

The patient was placed on a stretcher and given one litre of warmed water and three grammes of pthalylsulphathiazole orally. One mega unit of soluble penicillin was injected intramuscularly. His general condition improved over the hour following admission and he was encouraged to take frequent sips of water. He then vomited all the fluid and the pthalylsulphathiazole which he had been given. Chlorpromazine $50 \mathrm{mg}$ was injected intramuscularly; two grammes of pthalylsulphathiazole were given orally and he was encouraged to drink water. Four hours from the onset of his symptoms 


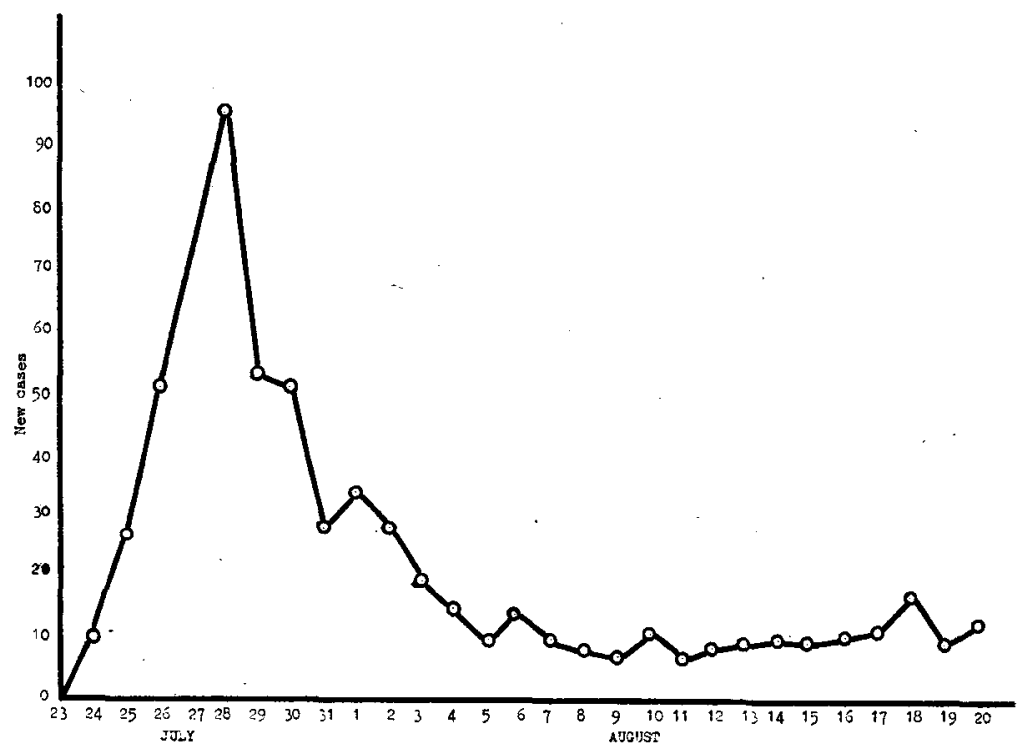

Fig. 1. Daily totals of new cases of diarrhoea.

he again vomited, complained of abdominal pain and passed about one litre of clear mucoid diarrhoea. He complained of feeling weak; his pulse rate had risen to one hundred and twenty per minute and was of low volume. He was less alert. Helicopter evacuation to R.A.F. Sick Quarters, El Adem was requested, the end of the stretcher was raised and intravenous infusion decided upon. The patient vomited copiously once more and passed an estimated litre of mucoid diarrhoea. As venepuncture was being performed the patient became ashen, his respiration ceased, no arterial pulsation was palpable and his heart sounds were inaudible. Normal saline was infused at maximum rate and he was sharply thumped over the lower end of the sternum. Within a minute a radial pulse became again palpable and breathing commenced. Over the next five hours three litres of normal saline and one of dextrose were infused. He was evacuated by air to Princess Mary's Royal Air Force Hospital, Cyprus, and has since returned to his unit. He is now quite well.

\section{Discussion}

Diarrhoea, occurring within a few days of arrival in a tropical or subtropical area, is accepted as being almost inevitable by most soldiers. It is however, apparent ihat some cases may be sufficiently severe to warrant full scale resuscitation. The necessary infusion sets, drugs, equipment and manpower should always be available to provide this. The use of intravenous fluids was undoubtedly life-saving in the case described. Their use is complicated by the tendency, under field conditions, of the needles to become extravascular. Five separate venepunctures were required to maintain the infusion described. Braun type cannulae would have been more satisfactory. Aneroid sphygmomanometers are more practical in the field as they are more robust than the mercury type. 
There are considerable nursing problems in caring for patients needing resuscitation who are concomitantly having diarrhoea and vomiting. Trained staff are invaluable as the needs of such patients can be attended to capably and with a minimum of disturbance to the patient.

The need to move a patient with diarrhoea to allow him to excrete could be obviated by cutting a hole in the stretcher at an appropriate level. It would be necessary to strengthen the rim of the hole with canvas. The use of such a prepared stretcher would contribute greatly to the patient's comfort, be less exhausting for him and allow better control of intravenous infusion. It is suggested that medical officers accompanying troops to remote areas where diarrhoea may be a problem should have such a stretcher available.

\section{ACADEMIC ACHIEVEMENTS}

M.R.C.P.(Lond.) M.R.C.O.G. D.Obst.R.C.O.G.

D.T.M. \& H.

D.I.H.

D.C.H. D.P.M.
Lieutenant-Colonel J. C. Wilson, M.B., B.Ch., B.A.o., D.T.M. \& H., R.A.M.C.

Major R. W. DUNCAN, M.B., Ch.B., D.obst.R.C.O.G., R.A.M.C.

Major J. C. C. Porter, M.B., B.S., R.A.M.C. Captain P. H. Carver, M.B., B.s., R.A.M.C.

Major F. K. BuCKLAND, M.R.C.S., L.R.C.P., R.A.M.C. MAJOR W. Holmes, M.B., B.S., D.P.H., R.A.M.C. MajoR A. C. Miller, M.B., ch.B., R.A.M.C. MAJOR F. P. THORESBY, M.B., B.S., R.A.M.C.

MAJOR G. M. STEWART, M.B., Ch.B., D.P.H., D.T.M. \& H., R.A.M.C.

MAJOR J. D. BELL, M.B., B.Ch., B.A.O., D.T.M. \& H., R.A.M.C.

Lieutenant-Colonel R. J. Belas, T.D., M.B., B.S., R.A.M.C. Major R. Wilson, M.B., ChB., D.T.M. \& H., R.A.M.C. 